Article

\title{
Determination of Environmental Factors for the Implementation of the Exploitability Index in Industrial Aggregate Mining Using Multi-Criteria Analysis
}

\author{
Julio Manuel de Luis-Ruiz ${ }^{1}$, Benito Ramiro Salas-Menocal ${ }^{1}$, Gema Fernández-Maroto ${ }^{2}$, Rubén Pérez-Álvarez ${ }^{1, *(D)}$ \\ and Raúl Pereda-García ${ }^{1}$ \\ 1 Cartographic Engineering and Mining Exploitation R+D+i Group, Polytechnic School of Mining and Energy \\ Engineering, University of Cantabria, 39300 Torrelavega, Spain; julio.luis@unican.es (J.M.d.L.-R.); \\ benito-r.salas@alumnos.unican.es (B.R.S.-M.); raul.pereda@unican.es (R.P.-G.) \\ 2 Department of Earth Sciences and Physics of the Condensed Matter, Polytechnic School of Mining and Energy \\ Engineering, University of Cantabria, 39300 Torrelavega, Spain; gema.fernandez@unican.es \\ * Correspondence: ruben.perez@unican.es
}

Citation: de Luis-Ruiz, J.M.;

Salas-Menocal, B.R.;

Fernández-Maroto, G.; Pérez-Álvarez

R.; Pereda-García, R. Determination

of Environmental Factors for the

Implementation of the Exploitability

Index in Industrial Aggregate Mining Using Multi-Criteria Analysis. ISPRS

Int. J. Geo-Inf. 2021, 10, 196.

https://doi.org/10.3390/ijgi10040196

Academic Editors: Wolfgang Kainz and Kazimierz Becek

Received: 27 January 2021

Accepted: 22 March 2021

Published: 24 March 2021

Publisher's Note: MDPI stays neutral with regard to jurisdictional claims in published maps and institutional affiliations.

Copyright: (c) 2021 by the authors. Licensee MDPI, Basel, Switzerland. This article is an open access article distributed under the terms and conditions of the Creative Commons Attribution (CC BY) license (https:// creativecommons.org/licenses/by/ $4.0 /)$

\begin{abstract}
The quality of human life is linked to the exploitation of mining resources. The Exploitability Index (EI) assesses the actual possibilities to enable a mine according to several factors. The environment is one of the most constraining ones, but its analysis is made in a shallow way. This research is focused on its determination, according to a new preliminary methodology that sets the main components of the environmental impact related to the development of an exploitation of industrial minerals and its weighting according to the Analytic Hierarchy Process (AHP). It is applied to the case of the ophitic outcrops in Cantabria (Spain). Twelve components are proposed and weighted with the AHP and an algorithm that allows for assigning a normalized value for the environmental factor to each deposit. Geographic Information Systems (GISs) are applied, allowing us to map a large number of components of the environmental factors. This provides a much more accurate estimation of the environmental factor, with respect to reality, and improves the traditional methodology in a substantial way. It can be established as a methodology for mining spaces planning, but it is suitable for other contexts, and it raises developing the environmental analysis before selecting the outcrop to be exploited.
\end{abstract}

Keywords: GIS; exploitability index; environmental factor; multi-criteria analysis; industrial aggregates; mining

\section{Introduction}

Social development is linked to the exploitation of mining resources. To achieve a sustainable exploitation, the development of increasingly detailed analysis about the feasibility of the mines and their potential affections has become more common [1].

In recent years, a concept known as Exploitability Index (EI) has begun to be applied. As its name notes, it is aimed at expressing the potential exploitability of a certain mining resource, on the basis of a series of factors, which may vary according to the authors: communications, environmental impact, mining regulations, economic investments, etc. [2]. Until recently, the analysis of all of these factors, including their components and influence, was carried out manually, with merely analogic tools. Hence, the researcher developed an algorithm with different tables that allowed for the attribution of a certain value to each deposit, which gave guidance and helped when making decisions. As it is obvious, since the process was developed by hand, it conditioned the number of factors and components that allowed for determining the EI and its corresponding adjustment to reality. The irruption in mining of software tools has allowed the application of multivariable analysis over time [3]. These works implied actions that were similar to those mentioned in the 
previous paragraph. However, the consolidation of Geographic Information Systems (GISs) has permitted linking the analysis aimed at calculating the EI with the territory, by means of cartography. In addition to the foregoing, since the process is computerized, and given the great capacity of the software to calculate and map, as many factors and components as desired can be included. In this regard, GIS have become transversal computer tools for many fields of human activity [4], in which the combination of the available information allows us to make adequate decisions, not only in mining, but in many operations that are developed on the territory. It should be mentioned that some of these decisions determine the success or failure of a certain project, or a noticeable improvement in the efficiency of an enterprise. The short lifespan and rapid evolution of these tools, and the variability of the factors that can be considered, justify a research that details an optimal methodology to develop this type of analysis, in which all the more relevant factors for the determination of the EI are adequately weighted (weighted analyses have proven to be more effective when compared with the non-weighted ones, as they provide more reliable results [5]). To this end, it is proposed to start from the basis of a definition of the EI that includes all the classic factors (reserves, accesses, weathering, environmental aspects, etc.), and from another new one that details all the components of the environmental factor, as it is undoubtedly the most relevant one among those that have been traditionally applied. All the foregoing is aimed at making the most adequate decision about the exploitation of a certain mining resource. Hence, it can be stated that the general objective of this research is the generation of a tool to make decisions, which, through strategic information, allows us to face a project of mining exploration with all the technical and economic warranties that a mining operation of this type requires, while maintaining the sustainability and respect for the environment as key objectives. The general aim is materialized through the specific objective, which implies the determination of the most suitable components and their weighting for the designation of an optimized environmental factor [6], which allows us to obtain the EI for a certain mining resource. It should be reminded that by definition, the EI considers other factors, such as social, economic, etc.

\section{Materials and Methods}

Nowadays, the rational use of the mining resources is one of the most important objectives for the human being. On the one hand, their utilization has important connotations for social welfare, and, on the other hand, that use must comply with the respect and preservation of the environment, and their sustainability [7]. The consideration of mining resources as elements that require protection has become increasingly common in land planning (mining preserves), so as to avoid unnecessary constrains which could disable areas with high potential and quality in terms of resources.

The knowledge of the land distribution of potentially exploitable resources is the key to achieve the integration of mining in land planning [8], and the best way to protect industrial minerals and rocks from activities and uses of the land that compromise their utilization in the future. The mineral resources have traditionally been defined by means of projects of mining exploration and research. They usually comprise the classic exploratory methods aimed at estimating reserves. In recent years, it has been noted that the estimation of reserves is not the only conditioning factor for the enablement of a mining exploitation [9], and this is the reason for the EI to emerge as an index that assesses the actual possibilities of implementing a mine, by taking into account many aspects that influence the final decision.

\subsection{Traditional Exploitability Indexes}

The extraction of mineral resources comes into conflict with other uses of land, especially in the case of industrial minerals, given their low prices and their abundance. In order to avoid these incompatibilities, a territorial planning that minimizes the cumulative impacts and considers all the criteria that take part into the process is required [10]. Study and research efforts have so far been focused on spatial planning, and they have been combined with GIS, the powerful software tools that have emerged in recent decades. 
The first works that analyzed the potential of the geological resources and took into account the environmental factors were developed in Germany in the 1970s [11]. The Hanover Geological Service generated geo-environmental and geo-scientific maps that were easy to understand by land planners.

In 1980, the method developed by Terán and Lastra [12] catalogued the different outcrops according to their possibilities of being exploited and their socio-economic interactions. Firstly, the hierarchization of the outcrops considers the factors that influence the possibilities of exploitation. From a geological point of view, it characterizes the deposit by defining the type of rock, its uniformity, the grade of rock weathering, the fracturing and diaclasing, the overburden thickness, the potential cavities, the natural slopes, etc. Secondly, factors such as the internal economic characteristics (including the calculation of reserves and the type of exploitation), the external economic characteristics, and the accessibility of the site have a significant impact on the value of the product, as well as the proximity to consumption centers. The distance between the outcrop and the point of supply is a determining factor. Finally, it considers socio-environmental conditions, such as population density, proximity to urban centers, current and planned land uses in spatial planning, economic activities in the area, etc.

Since 1993, the Geological and Mining Institute of Spain has been developing the "mining-environmental management of mineral resources". It is aimed at establishing the basis for the optimization of the exploitation of mining resources and the minimization of the environmental impact. A new map of mining and environmental management is designed with the support of GIS. It applies a methodology of impact/aptitude for mining activity [13] that includes concepts such as "exclusion", "inclusion", zonal analysis, etc., which are the most elementary basis of this research. These maps of Mining and Environmental Management are the essential cartographic support for the integration of mining resources and activities in land planning. They depict a zoning of the lands with mining resources according to the feasibility of their exploitation, and considering mining and environmental criteria.

Considering the methodologies proposed by Oliveira Sousa [14], Muñoz de la Nava et al. [15], and other authors, six parameters must be set for each outcrop. Field works and economic considerations demonstrated that these six factors were the most important features to characterize their exploitability. Among the many variables that can intervene, the most relevant ones when it comes to exploiting a resource are the quality of the material (rock properties), the geographical location of the outcrop (proximity to population and accesses), its size, the morphology of the terrain and the degree of surface weathering.

During the first decade of the current century, techniques of distributed modelling were applied with GIS, along with multi-criteria analysis (MCA) for decision support [16]. Databases have been implemented for the evaluation of risks in mining sites [17]. Recently, techniques of multi-criteria analysis with GIS have been applied, to assess the environmental impact of mining activities [18].

Considering the direct background of this research, two works must be mentioned. The first one [19] presented a methodology to integrate the potential mining exploitation into its surroundings, by prioritizing those with less environmental impact. From this research, a new proposal for the determination of the EI was derived [9], which considers the morphology of the terrain, road and rail access, weathering, available reserves and the environmental impact of the hypothetical mining exploitation. It allows for the calculation of the Ie values (1) with the spatial criteria, whose values are obtained with GIS, and the factors that are subjectively established in the field.

$$
\mathrm{I}_{\mathrm{e}}=\frac{\sum\left(\mathrm{K}_{\mathrm{i}} \cdot \mathrm{V}_{\mathrm{i}}\right)}{\mathrm{I}_{\max }} \cdot 100
$$

where $\mathrm{I}_{\mathrm{e}}$ is the EI, $\mathrm{K}_{\mathrm{i}}$ is the weighting coefficients, $\mathrm{V}_{\mathrm{i}}$ is the hierarchizing coefficients and $\mathrm{I}_{\max }=4 \cdot \sum \mathrm{K}_{\mathrm{i}}$. 
After determining the $\mathrm{V}_{\mathrm{i}}$ values for each parameter and applying the appropriate weighting coefficients $\left(\mathrm{K}_{\mathrm{i}}\right)$, the $\mathrm{I}_{\mathrm{e}}$ is calculated for each outcrop according to (1), which finally provides a quantitative assessment.

From its origins to the most complex multi-criteria analysis that are carried out with GIS in recent times, all the methodologies for the determination of the EI take into account the environmental considerations as the most relevant ones, and assign them the greatest weights for the calculation of the index. However, it seems noticeable that these aspects are treated with more generic criteria, as it happens in the case of the last methodology that was described [9]: The only environmental criteria are classified according to whether the area is away from communities or roads with or without legal restrictions, which is an excessively general analysis.

It is precisely in this field where the present investigation operates: the analysis of the behavior of the different components that influence the environmental criterion, which is the one with the greatest weight among those used in this type of multi-criteria analysis. The elaboration of a research of this type at regional scale must be dynamic, flexible, reviewable and adapted to the different situations that may arise, but it must be rigorous in its conceptual principles. Despite the availability of different models, they are analogous to each other. There is not a universal and unique method for this type of study, since many particular aspects of each research area and resource have influence (a gravel pit is not the same as a slate pit, etc.). However, a trend to apply concepts such as aptitude or geological and mining potential to improve the simple delimitation of the zones that contain resources does exist. These factors or concepts are essential for the evaluation of the suitability of the territory, and its mining and environmental planning [20].

\subsection{Methodological Proposal to Redefine the Environmental Criterion}

Unlike other types of human activities in which the optimal location can be studied and analyzed for their implementation within an area, the commissioning of any extractive activity is conditioned by the location and existence of mining resources. This is especially true for the mining of metals and energetic resources, where the activity site is predetermined by the location of resources. When these cases are presented, there is no other analysis than that of the economic and environmental feasibility of the mining project in the only possible location, which is the one where the deposit is located. However, there are some types of rocks and industrial minerals that are found in nature with a more abundant distribution. In these cases, the study and analysis of alternative locations for the mining activity within the regional scope can be proposed, according to all the factors of the social, physical, economic, environmental and geographical contexts, to those that are intrinsic to the resource to be exploited, and considering the degree of compatibility of its location with other uses of the natural resources and the existing legislation [21].

As described above, and given that the environmental factor has the greatest weight in the calculation of the EI, it is convenient to divide this criterion into components that, while being as faithful to reality as possible, make it possible to improve the general procedure to define the optimal location [1], which is the main aim of the research. The concept of components of the environment, which sustains the development of life on the planet and human activities, includes those that are susceptible of being modified by humankind. These changes may be severe enough to cause serious problems in the environment. These components are divided into three major groups, which are subdivided into subgroups. These subgroups are divided again, and these subgroups must be selected according to criteria of relevance, reliability and commensurability. It is not advisable to exceed four levels of disaggregation, which are adequate for most projects [13].

- Socio-economic subsystem: It refers to the population and its attributes as consumer of goods and services, and subject of social relations and cultural activities.

- Nuclei and infrastructures subsystem: It is constituted by human settlements, infrastructures and their exchange relations. 
- Natural physical subsystem: It is probably the most relevant of the three groups, and it is constituted by the land and resources in their present form.

This research proposes a methodology that permits combining all the components that are desired to utilize in the calculation of the environmental factor. As it is described later, in Section 2.2.1, they can vary, and given the number of components and criteria that can be considered, the application of a multi-criteria analysis is proposed to set the most adequate combination of all the components chosen.

\subsubsection{Definition of Components}

This section presents the main components that were adopted for the practical case with which the methodological proposal is contrasted. It must be considered that, given the different types of deposits that could be evaluated by means of this methodology, the components that were considered for this particular case could differ from those that would be suitable for application in other circumstances. As it is obvious, they will depend on the resource to be assessed, and the boundary conditions of its surroundings. However, this fact does not prevent the methodological proposal from being fully valid. The definition of the essential components of the environmental factor itself does not include very relevant factors, such as the social or economic ones, the reserves estimation, the quality of the resource, etc. However, they are considered in the calculation of the EI, and have been properly treated in other works [9]. The definition of components of the environmental factor is made according to the impacting actions that are caused by the aggregate extraction industries during the exploitation and reclamation stages [22]. Depending on the scale of work at the regional level, the components to be used must be in accordance with the available study data, and suitable for their depiction with GIS-type tools. That is to say, they must be geographically linked data. In this regard, the environmental components are applied to point outcrops, even though the latter have a superficial component. This is due to the fact that, during this stage of the mining prospection, the outcrops were not delimited, and the spatial correlation justifies that the variations in the results are relatively small. As a result of the research that was carried out, the most significant components of the environmental impact studies in mining areas are established below. In short, they constitute the methodological proposal of this research. As it can be observed Table 1, only three levels of disaggregation are applied, as they are considered more than sufficient.

Table 1. Relation of components that are applied in this research.

\begin{tabular}{ccc}
\hline Level 1 & Level 2 & Level 3 \\
\hline & Inert medium & $\begin{array}{c}\text { Air } \\
\text { Ground-soil } \\
\text { Water }\end{array}$ \\
\cline { 2 - 3 } Natural physical subsystem & Biotic medium & $\begin{array}{c}\text { Vegetation } \\
\text { Fauna }\end{array}$ \\
& Perceivable medium & Special ecosystems \\
\cline { 2 - 3 } & Land uses & $\begin{array}{c}\text { Landscape } \\
\text { Scientific-cultural assets }\end{array}$ \\
\cline { 2 - 3 } Socio-economic subsystem & Population & Productive uses \\
\hline Nuclei and infrastructures & Infrastructures and services & Density of population \\
\cline { 2 - 3 } subsystem & Urban structure & Road network \\
\cline { 2 - 3 } & & Urban planning \\
\hline
\end{tabular}


Each of these components are described below.

- Air: Mining affects this component mainly by the emission of solid particles, dust, gases and noise pollution during the excavation of holes, the stockpiling of materials, the creation of dumps, and due to the traffic of heavy loading and hauling equipment. [23].

- Ground-soil: Mining irreversibly affects the soil, which turns this component into one of the most relevant when assessing the environmental factor. The assessment is developed by means of the analysis of the active geomorphological processes (landslides, erosion, flooding, subsidence, etc.). The areas where these processes are more active are considered as less suitable, and those less active, as more adequate for mining activities. For example, the creation of voids, dumps, and the construction of tracks, buildings and treatment plants, have negative edaphic effects on the exploitation surroundings, due to the accumulation of wastes, fine elements and dust [24].

- Water: Mining affects surface water causing turbidity due to solid particles, dissolved toxic elements, acidification derived from the oxidation of pyrite components [1], etc. In this sense, all the conditions suffered by surface water also affect the groundwater [25]. In addition to this, the dumps, the creation of holes and excavations, and the pumping of water out of mine workings below the water table can alter aquifers and their flow regimes, which can be polluted by oils and hydrocarbons from heavy machinery [26].

- Vegetation: Mining removes or reduces the vegetation cover, and hinders its regeneration, due to the loss of fertile elements associated to the drastic increases of slopes and the erosion [27].

- Fauna: Mining has an impact on fauna, mainly by affecting their terrestrial habitats, provoking the displacement or concentration of species and individuals, excavating holes, and especially, by generating dumps. In addition to the foregoing, it can change behavior patterns of the fauna due to the disturbances related to heavy machinery traffic and the creation of tracks and infrastructures [28].

- Special ecosystems: Mining and all its inherent activities may severely affect this type of ecosystems, whose wildlife protection is the ultimate objective aimed by the definition of this kind of protecting areas [29].

- Landscape: Mining causes global disturbances in the landscape. These disruptions are generally grave in the case of dumps, severe when considering mining holes, and temporary with respect to the impacts associated to constructions, buildings, and the implantation of infrastructure [30].

- Scientific-cultural assets: Although extractive activities can promote the development of mining heritage, they can imply irreversible consequences for other types of cultural, historical, artistic or scientific elements. For a proper conservation, a regional catalogue that includes the assets of cultural interest is needed [31].

- Land uses: The territory is classified by the legislator according to its constraints with respect to its utilization (agriculture, forestry uses, etc.). If the mining activities are not developed in an area that is especially classified for this use, a change in the classification of the land and its degrees of protection is required [32].

- Population: The attitude of the population towards a mining project produces an important environmental factor called social acceptance. Mining projects that achieve social acceptance have a positive impact from an economic point of view and, in a negative way, can alter significant places, such as cultural and social heritage sites with unique value [33].

- $\quad$ Road network: Mining activity increases the traffic density on public roads, which puts the population at risk of a possible growth in the number of accidents, the deterioration of road surfaces and muddy roads. Socio-economically depressed areas can also benefit from the construction of new infrastructure required for the development of such activities [34]. 
- Urban planning: To start a mining project, its viability must pass through three basic legislative filters, namely mining legislation, environmental legislation, and urban planning legislation [35]. The classification of the land that is usually defined by the municipalities sets the type of activities that can be developed there. Sometimes, the mining project needs a modification in the land use so as to become effective.

\subsubsection{Methodological Proposal}

The methodological proposal is based on the map algebra, one of the potentialities of GIS tools. The aim is to calculate the environmental factor that an exploitation of industrial aggregates or ornamental rocks produces in its location and its area of influence, so as to introduce it in the calculation of the EI. This factor and the index are linked to the territory by means of georeferencing. The model is built on the basis of the twelve environmental components that were proposed in the previous section and are the most significant in the area of study.

Firstly, a zoning map of each impact is made for each component of the chosen environment. After obtaining the impact maps, their arithmetic superposition is proposed. To this end, the sum operator is proposed, but affected by a weighting coefficient, which is introduced because all the possible impacts cannot imply the same degree of affection, as some of them are reversible and others are not, some allow the introduction of corrective measures but in other cases they are not possible, etc. The arithmetic expression is the following one:

$$
\mathrm{I}_{\mathrm{T}}=\sum_{\mathrm{i}}^{\mathrm{i}} \mathrm{K}_{\mathrm{i}} \cdot \mathrm{I}_{\mathrm{Pi}}
$$

where $I_{T}$ is the Total Impact, $K_{i}$ are the weighting coefficients expressed as parts per unit, and $\mathrm{I}_{\mathrm{Pi}}$ is the Partial Impact of each component.

To obtain the weighting coefficient, the application of the multi-criteria method known as Analytic Hierarchy Process (AHP) is proposed [36]. This method was developed by Professor Thomas L. Saaty, and, by means of a matrix of compared pairs and its corresponding normalized matrix, it allows us to apply an analytic process, to obtain the weighting coefficient for each component with objective criteria [37].

Saaty Fundamental Scale (Table 2) is applied to carry out the paired comparison. It allows us to turn qualitative aspects into quantitative, and significantly facilitates comparison between components, providing more objective and reliable results.

Table 2. Saaty Fundamental Scale for pairwise comparison [37].

\begin{tabular}{|c|c|c|}
\hline Scale & Definition & Explanation \\
\hline 1 & Same importance & $\begin{array}{l}\text { Both criteria contribute to the objective in the } \\
\text { same way. }\end{array}$ \\
\hline 3 & $\begin{array}{l}\text { Moderated } \\
\text { importance }\end{array}$ & $\begin{array}{c}\text { Experience and judgment slightly favor one criterion } \\
\text { over the other. }\end{array}$ \\
\hline 5 & Great Importance & $\begin{array}{c}\text { Experience and judgment strongly favor one criterion } \\
\text { over the other. }\end{array}$ \\
\hline 7 & $\begin{array}{l}\text { Very great } \\
\text { importance }\end{array}$ & $\begin{array}{l}\text { One criterion is very strongly favored over the other. } \\
\text { In practice, its dominance can be demonstrated. }\end{array}$ \\
\hline 9 & Extreme importance & $\begin{array}{l}\text { Evidence favors one factor over the other to the } \\
\text { fullest extent. }\end{array}$ \\
\hline $2,4,6$ and 8 & \multicolumn{2}{|c|}{$\begin{array}{l}\text { Intermediate values between the ones that are mentioned above, when } \\
\text { qualifying is required. }\end{array}$} \\
\hline
\end{tabular}

After defining the components of the matrix, the pairwise analysis is performed. After comparing all the components, this matrix is normalized.

Its rows are added and each sum is averaged to obtain the vector of average sums or global priorities. The original matrix is multiplied by the vector of global priorities, and the total row vector is obtained. This row vector is divided by the vector of global 
priorities, obtaining from this quotient a column matrix. All the elements of this column matrix are added and averaged. With the average value obtained $\left(\lambda_{\max }\right)$ and taking into account the number of components used in the matrix (n), the Coefficient of Inconsistency (CI) is calculated (3).

$$
\mathrm{CI}=\left(\lambda_{\max }-\mathrm{n}\right) /(\mathrm{n}-1)
$$

where $\mathrm{CI}$ is the Coefficient of Inconsistency, $\lambda_{\max }$ is the average of the elements of the column matrix, and $\mathrm{n}$ is the number of matrix components.

Finally, the obtained CI is compared with the random consistency values (ICAs), which are the values that $\mathrm{CI}$ should obtain if the numerical judgments introduced in the original matrix were random within the scale $1 / 9,1 / 8,1 / 7 \ldots 1 / 2,1,2, \ldots, 7,8,9$. The values of the random consistency as a function of the rank of the matrix are shown in Table 3 [38].

Table 3. Random consistency values according to the rank of the matrix.

\begin{tabular}{ccccccccccc}
\hline $\mathbf{n}$ & $\mathbf{3}$ & $\mathbf{4}$ & $\mathbf{5}$ & $\mathbf{6}$ & $\mathbf{7}$ & $\mathbf{8}$ & $\mathbf{9}$ & $\mathbf{1 0}$ & $\mathbf{1 1}$ & $\mathbf{1 2}$ \\
\hline ICA & 0.525 & 0.882 & 1.115 & 1.252 & 1.341 & 1.404 & 1.452 & 1.484 & 1.513 & 1.535 \\
\hline
\end{tabular}

ICA, random consistency value.

The random consistency is chosen according to the number of components of the matrix, in order to subsequently calculate the Consistency Ratio (RC) as the quotient between the calculated CI and the random consistency (4).

$$
\mathrm{RC}=\mathrm{CI} / \mathrm{ICA}
$$

Consistency is considered to exist when the RC does not exceed the percentages shown in Table 4 [39]. If it is higher, the matrix of pairs should be re-evaluated.

Table 4. Values of the Consistency Ratio, according to the rank of the matrix.

\begin{tabular}{cc}
\hline Rank of the Matrix & Consistency Ratio \\
\hline 3 & $\leq 5 \%$ \\
4 & $\leq 9 \%$ \\
$\geq 5$ & $\leq 10 \%$ \\
\hline
\end{tabular}

Although the RC guarantees that the matrix is consistent, in order to improve the assignment of weights of each component to be used in the map algebra of the model, the procedure that is applied to determine the global priorities can be iterated until two consecutive iterations provide values as similar as desired.

Once the assignment of weights for each component is established, all the components must be evaluated within the same delimited values. The range between 1 and 5 is proposed. This allows us to define a uniform working scale to assign values to the areas of influence to be applied in each component of the environmental impact chosen for the model (Table 5).

Table 5. Quantitative-qualitative conversion of the Index of Environmental Impact.

\begin{tabular}{ccc}
\hline Criterion & Value \\
\hline Very low & 1 \\
Low & 2 \\
Moderate & 3 \\
High & \multicolumn{2}{c}{4} \\
Very high & 5 \\
\hline
\end{tabular}




\section{Results}

\subsection{Introduction}

The methodology that was presented above is proposed for application in the Autonomous Community of Cantabria, a region of Spain (Figure 1) that is characterized by its richness in industrial aggregates, and especially in ophites. The production of excellent aggregates for concrete manufacturing, their use in road wearing courses, and especially as railroad ballast, can be presented as some relevant applications of these rocky materials. Hence, the spatial extent of the impact is focused on the regional scope of the Autonomous Community, although each component has its own extent. The choice of this area is aimed at contrasting the results of this research with those of another work that was carried out by this same research group three years ago [9]. As it is obvious, the latter only considered the classic environmental criterion.

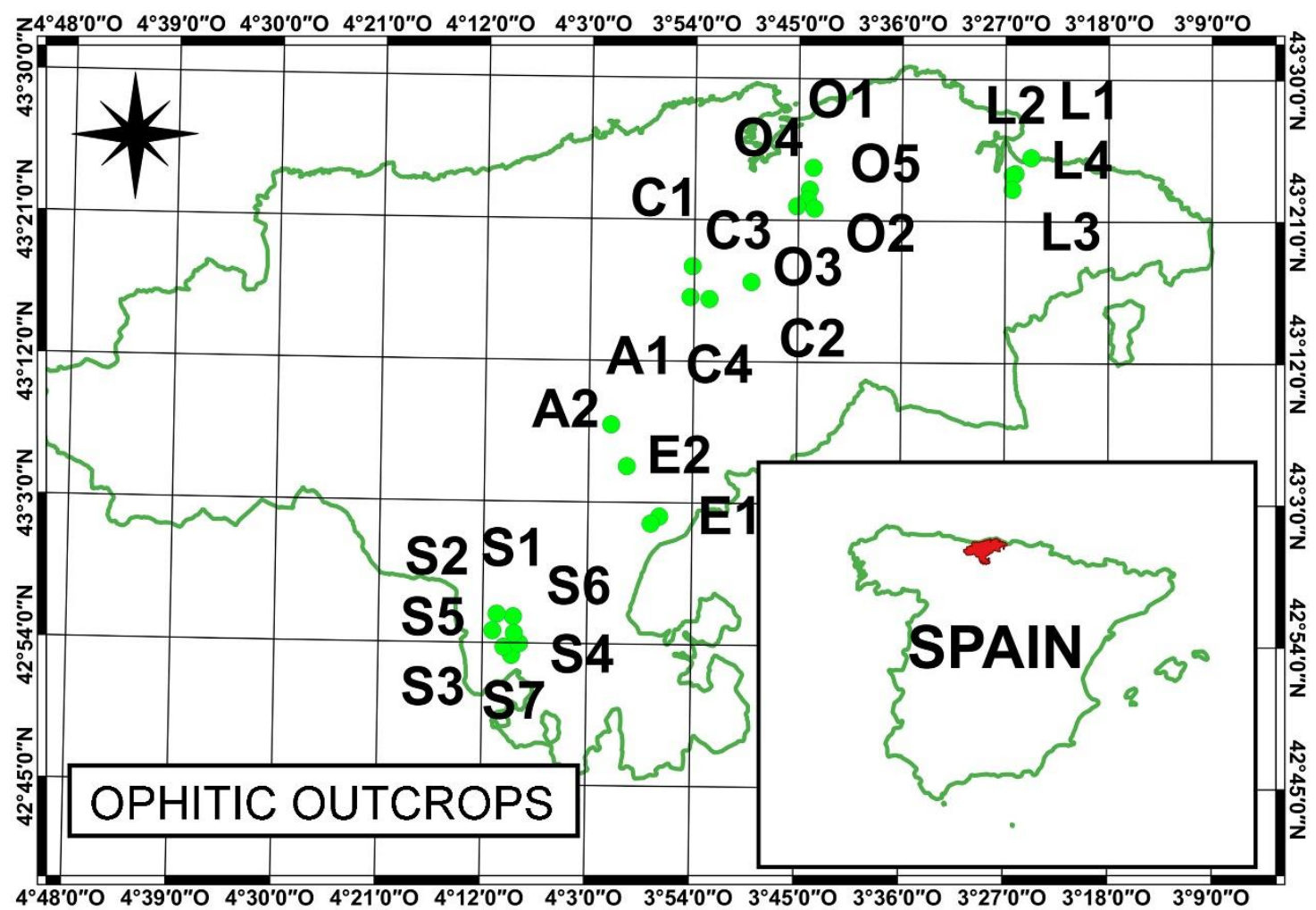

Figure 1. Territorial context of Cantabria in Spain and location of the ophitic outcrops. Area of Laredo: El Canto (L1), Peña Lucía (L2), Colindres (L3) and Limpias (L4). Area of Orejo: Orejo (O1), Solares (O2), Sobremazas (O3), Anaz (O4) and Hermosa (O5). Central Area: San Román (C1), Esles (C2), Sandoñana (C3) and Escobedo (C4). Area of Alsa: Cueto Pando (A1) and the Alsa Reservoir (A2). Area of Ebro: Ebro Reservoir (E1) and La Población (E2). South Area: San Martín de Hoyos (S1), Olea (S2), Castrillo del Haya (S3), Rebolledo (S4), Camesa (S5), Matarrepudio (S6) and El Haya (S7).

Given the existence of numerous ophitic outcrops in Cantabria, they can be considered as strategic resources for regional development. However, due to their abundance, before starting an exhaustive study of each deposit, it is necessary to prioritize the most interesting ones within the best conditions of profitability and environmental conservation. For this reason, and from the general study of all the ophitic outcrops existing in the region, they are grouped into six zones, according to criteria of proximity and similarity: 
- Area of Laredo: It comprises the northernmost outcrops of the region. Four different outcrops can be distinguished, namely El Canto (L1), Peña Lucía (L2), Colindres (L3) and Limpias (L4).

- Area of Orejo: Five different outcrops can be distinguished in the area, namely Orejo (O1), Solares (O2), Sobremazas (O3), Anaz (O4) and Hermosa (O5).

- Central Area: It includes the outcrops in the central zone of the region. Four different outcrops can be distinguished, namely San Román (C1), Esles (C2), Sandoñana (C3) and Escobedo (C4).

- Area of Alsa: It comprises the outcrops of Cueto Pando (A1) and the Alsa Reservoir (A2).

- Area of Ebro: It includes the ophitic outcrops near the Ebro Reservoir (E1) and La Población (E2).

- South Area: It includes an important number of outcrops in the south of the region, namely San Martín de Hoyos (S1), Olea (S2), Castrillo del Haya (S3), Rebolledo (S4), Camesa (S5), Matarrepudio (S6) and El Haya (S7).

All the outcrops are identified with points. This consideration is due to the common unavailability of detailed geologic cartography during this stage of mining exploration that allows us to define the perimeter of the outcrop. In addition to this, the size of the ophitic outcrops in Cantabria is relatively small. In fact, they are even smaller than the spatial resolution of the raster files that were applied for the analysis with GIS $(55 \mathrm{~m} \times 33 \mathrm{~m})$. Hence, it can be stated that the working scale allows us to consider the outcrops as point elements.

\subsection{Matrix of Pairwise Comparison and Weighting of Components}

According to the proposed methodology, and starting from the components of the environmental impact (Table 1), the matrix of compared pairs is obtained by applying Saaty Fundamental Scale (Table 2). This matrix is characterized by being square, and it also has the following properties.

- $\quad$ Reciprocity, if $a_{i j}=x$, then $a_{j i}=1 / x$.

- Homogeneity, if $\mathrm{i}$ and $\mathrm{j}$ are equally important, then $\mathrm{a}_{\mathrm{ij}}=\mathrm{a}_{\mathrm{ji}}=1$.

- By definition, $a_{i i}=1$ for any $i$.

- Consistency: The matrix must not contain contradictions in the valuation performed.

It should be noted that it is in the pairwise comparison of the components that the criteria of importance of one component over another must be established, and therefore, where experience plays a fundamental role, given that the entire strength of the method rests on this pairwise comparison matrix, and this is checked through the consistency ratio of the matrix itself. Based on the previous experience of the research group in this matter, and aspects such as the current legislation, the duration of the impacts and the corrective measures that can be applied to minimize these impacts in this type of exploitation, etc., we propose a pairwise comparison matrix, which is shown in Table 6.

Once the matrix of pairwise comparison is created, it is normalized by establishing a new matrix of the same order as the compared matrix, as described in the methodological proposal (Table 7).

After determining the global priorities (assignment of weights for each component) and the column matrix, the next step is to demonstrate the consistency or inconsistency of the matrix by applying the procedure designed in the methodological proposal (Table 8). 
Table 6. Matrix of pairwise comparison for the ophitic outcrops in Cantabria.

\begin{tabular}{ccccccccccccccc}
\hline Component & & $\mathbf{A}$ & $\mathbf{B}$ & $\mathbf{C}$ & $\mathbf{D}$ & $\mathbf{E}$ & $\mathbf{F}$ & $\mathbf{G}$ & $\mathbf{H}$ & $\mathbf{I}$ & $\mathbf{J}$ & $\mathbf{K}$ & $\mathbf{L}$ \\
\hline Air & $\mathrm{A}$ & 1 & 1.00 & 0.33 & 0.33 & 0.33 & 0.20 & 0.33 & 1.00 & 0.20 & 1.00 & 1.00 & 0.20 \\
Ground-Soil & $\mathrm{B}$ & 1.00 & 1 & 0.33 & 1.00 & 1.00 & 0.20 & 0.50 & 2.00 & 0.20 & 2.00 & 0.50 & 0.20 \\
Water & $\mathrm{C}$ & 3.00 & 3.00 & 1 & 2.00 & 1.00 & 0.20 & 3.00 & 3.00 & 0.25 & 2.00 & 5.00 & 0.33 \\
Vegetation & $\mathrm{D}$ & 3.00 & 1.00 & 0.50 & 1 & 1.00 & 0.20 & 2.00 & 2.00 & 0.25 & 2.00 & 2.00 & 0.33 \\
Fauna & $\mathrm{E}$ & 3.00 & 1.00 & 1.00 & 1.00 & 1 & 0.20 & 2.00 & 2.00 & 0.25 & 2.00 & 2.00 & 0.33 \\
Special Ecosystems & $\mathrm{F}$ & 5.00 & 5.00 & 5.00 & 5.00 & 5.00 & 1 & 5.00 & 5.00 & 1.00 & 5.00 & 5.00 & 5.00 \\
Landscape & $\mathrm{G}$ & 3.00 & 2.00 & 0.33 & 0.50 & 0.50 & 0.20 & 1 & 3.00 & 0.25 & 2.00 & 3.00 & 2.00 \\
Productive Uses & $\mathrm{H}$ & 1.00 & 0.50 & 0.33 & 0.50 & 0.50 & 0.20 & 0.33 & 1 & 0.20 & 1.00 & 2.00 & 0.33 \\
Areas of Scientific-Cultural Interest & $\mathrm{I}$ & 5.00 & 5.00 & 4.00 & 4.00 & 4.00 & 1.00 & 4.00 & 5.00 & 1 & 5.00 & 5.00 & 4.00 \\
Density of Population & $\mathrm{J}$ & 1.00 & 0.50 & 0.50 & 0.50 & 0.50 & 0.20 & 0.50 & 1.00 & 0.20 & 1 & 0.50 & 0.25 \\
Road Network & $\mathrm{K}$ & 1.00 & 2.00 & 0.20 & 0.50 & 0.50 & 0.20 & 0.33 & 0.50 & 0.20 & 2.00 & 1 & 0.33 \\
Urban Planning & $\mathrm{L}$ & 5.00 & 5.00 & 3.00 & 3.00 & 3.00 & 0.20 & 0.50 & 3.00 & 0.25 & 4.00 & 3.00 & 1 \\
\hline
\end{tabular}

Table 7. Normalized matrix of pairwise comparison (first iteration).

\begin{tabular}{|c|c|c|c|c|c|c|c|c|c|c|c|c|c|c|c|}
\hline & A & B & $\mathrm{C}$ & D & E & F & G & $\mathbf{H}$ & I & $\mathbf{J}$ & $\mathbf{K}$ & L & $\begin{array}{c}\text { Global } \\
\text { Priorities }\end{array}$ & $\begin{array}{c}\text { Row } \\
\text { Vector }\end{array}$ & $\begin{array}{l}\text { Column } \\
\text { Matrix }\end{array}$ \\
\hline $\mathrm{A}$ & 0.03 & 0.04 & 0.02 & 0.02 & 0.02 & 0.05 & 0.02 & 0.04 & 0.05 & 0.03 & 0.03 & 0.01 & 0.0296 & 0.3719 & 12.5739 \\
\hline B & 0.03 & 0.04 & 0.02 & 0.05 & 0.05 & 0.05 & 0.03 & 0.07 & 0.05 & 0.07 & 0.02 & 0.01 & 0.0406 & 0.5087 & 12.5300 \\
\hline $\mathrm{C}$ & 0.09 & 0.11 & 0.06 & 0.10 & 0.05 & 0.05 & 0.15 & 0.11 & 0.06 & 0.07 & 0.17 & 0.02 & 0.0875 & 1.1555 & 13.2037 \\
\hline $\mathrm{D}$ & 0.09 & 0.04 & 0.03 & 0.05 & 0.05 & 0.05 & 0.10 & 0.07 & 0.06 & 0.07 & 0.07 & 0.02 & 0.0590 & 0.7636 & 12.9472 \\
\hline $\mathrm{E}$ & 0.09 & 0.04 & 0.06 & 0.05 & 0.05 & 0.05 & 0.10 & 0.07 & 0.06 & 0.07 & 0.07 & 0.02 & 0.0615 & 0.8074 & 13.1281 \\
\hline $\mathrm{F}$ & 0.16 & 0.19 & 0.30 & 0.26 & 0.27 & 0.25 & 0.26 & 0.18 & 0.24 & 0.17 & 0.17 & 0.35 & 0.2317 & 3.2422 & 13.9917 \\
\hline G & 0.09 & 0.07 & 0.02 & 0.03 & 0.03 & 0.05 & 0.05 & 0.11 & 0.06 & 0.07 & 0.10 & 0.14 & 0.0679 & 0.9231 & 13.5898 \\
\hline $\mathrm{H}$ & 0.03 & 0.02 & 0.02 & 0.03 & 0.03 & 0.05 & 0.02 & 0.04 & 0.05 & 0.03 & 0.07 & 0.02 & 0.0331 & 0.4227 & 12.7865 \\
\hline I & 0.16 & 0.19 & 0.24 & 0.21 & 0.22 & 0.25 & 0.21 & 0.18 & 0.24 & 0.17 & 0.17 & 0.28 & 0.2077 & 2.8505 & 13.7219 \\
\hline $\mathrm{J}$ & 0.03 & 0.02 & 0.03 & 0.03 & 0.03 & 0.05 & 0.03 & 0.04 & 0.05 & 0.03 & 0.02 & 0.02 & 0.0300 & 0.3855 & 12.8670 \\
\hline $\mathrm{K}$ & 0.03 & 0.07 & 0.01 & 0.03 & 0.03 & 0.05 & 0.02 & 0.02 & 0.05 & 0.07 & 0.03 & 0.02 & 0.0357 & 0.4497 & 12.6147 \\
\hline $\mathrm{L}$ & 0.16 & 0.19 & 0.18 & 0.16 & 0.16 & 0.05 & 0.03 & 0.11 & 0.06 & 0.14 & 0.10 & 0.07 & 0.1158 & 1.5489 & 13.3792 \\
\hline
\end{tabular}

Table 8. Results of the consistency analysis of the normalized matrix (first iteration).

\begin{tabular}{cc}
\hline Parameter & Value \\
\hline$\lambda_{\max }$ & 13.1111 \\
CI & 0.1010 \\
ICA (Table 3) & 1.535 \\
RC & $6.58 \%$ \\
\hline
\end{tabular}

CI, Coefficient of Inconsistency. RC, Consistency Ratio.

Knowing that the matrix has 12 components, more than 5, the consistency ratio must be less than $10 \%$ (Table 4 ). Given that the calculated consistency ratio was $6.58 \%$, which is less than $10 \%$, it can be assured that the matrix is consistent, and therefore the assignment of weights established in the global priorities is valid. However, as explained in the methodological proposal, the results of both the global priorities and the consistency of the matrix itself can be improved by means of an iteration. The results obtained at the fifth iteration, in which the global priorities have no significant variations, are shown in Table 9. 
Table 9. Results of the normalized matrix of pairwise comparison (fifth iteration).

\begin{tabular}{clcccc}
\hline & & Global Priorities & Total Row Vector & Column Matrix & Final Weight (\%) \\
\hline Air & A & 0.0277 & 0.3637 & 13.1080 & 2.77 \\
Ground-Soil & B & 0.0379 & 0.4968 & 13.1080 & 3.79 \\
Water & C & 0.0855 & 1.1207 & 13.1080 & 8.55 \\
Vegetation & D & 0.0568 & 0.7452 & 13.1080 & 5.68 \\
Fauna & E & 0.0601 & 0.7879 & 13.1080 & 6.01 \\
Special Ecosystems & F & 0.2424 & 3.1779 & 13.1080 & 24.24 \\
Landscape & G & 0.0684 & 0.8970 & 13.1080 & 6.84 \\
Productive Uses & H & 0.0315 & 0.4129 & 13.1080 & 3.15 \\
Areas of Scientific-Cultural Interest & I & 0.2131 & 2.7929 & 13.1080 & 21.31 \\
Density of Population & J & 0.0289 & 0.3789 & 13.1080 & 2.89 \\
Road Network & K & 0.0334 & 0.4381 & 13.1080 & 3.34 \\
Urban Planning & L & 0.1141 & 1.4961 & 13.1080 & \\
\hline
\end{tabular}

If the differences between the weights assigned in the first and fifth iterations are compared, it can be observed that the maximum variation is about $1 \%$ for the component related to special ecosystems. Although this variation is small, it must be taken into account for the application of the map algebra. A new justification of the consistency of the matrix is not required, since it also improves. This improvement is very slight, as the variations in the assignment of weights are very small.

\subsection{Determination of the Maps of Impact}

To start the preparation of these maps, a base map in vector format is adopted. It consists of a polygon with the boundaries of the region, and it is given a value of one for the impact, since there is no zero impact in mining. The second reference file is the map in vector format of the ophitic outcrop points. It is used to consult the impact values by projecting it on the thematic maps. After that, the maps corresponding to the twelve components of the environment are determined, to finally project them in raster format and to be able to apply the final weighting, according to Table 9. The final map obtained from this logical operation makes it possible to determine the final impact value for each component. As described in the methodological proposal, all the components are valued between 1 and 5 , to standardize the final results.

\subsubsection{Map of Air Impact}

One of the main problems of an aggregate quarry is the emission of dust and gases. Although there are corrective measures, its effect on nearby inhabited areas is the most pronounced negative point, which causes social rejection. As this aspect is essential for the development of the project, the distance to population centers is a determining factor for this component of the environment.

The map of air impact (Figure 2a) takes into account the areas of influence with radii of 500, 1500, 2000 and $2500 \mathrm{~m}$ around the urban centers, assigning values of 5, 4, 3 and 2, respectively. This classification is deduced from a work that is focused on the propagation of dust clouds and gases in the atmosphere [40]. This map, which is called "air", is converted to raster format according to the previously assigned values. Hence, a map with all its surface classified from 1 to 5 is obtained. This map is the one used for the map algebra. In order to check the results of the methodology, the map with the outcrop points is projected on the raster map. The value of this component is obtained for each outcrop point, as shown in Table 10. 


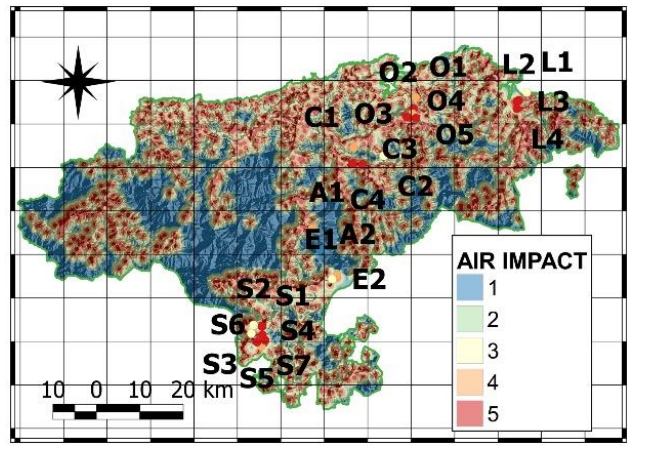

(a)

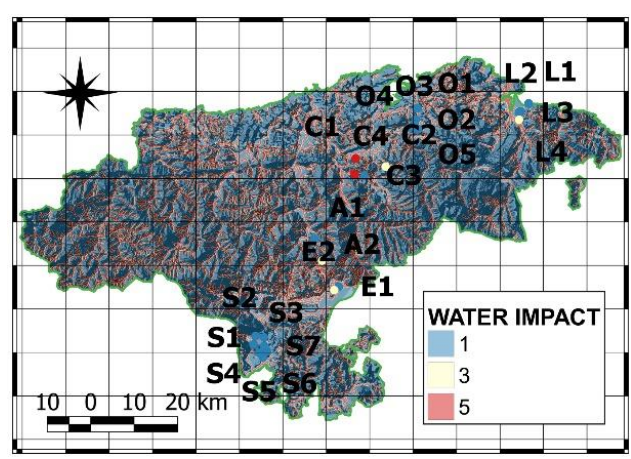

(c)

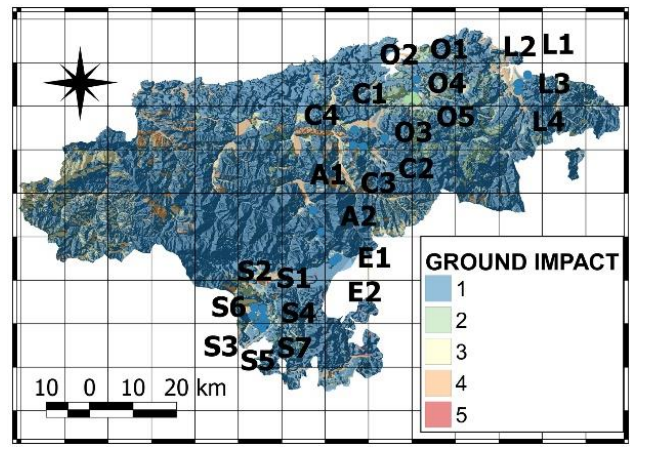

(b)

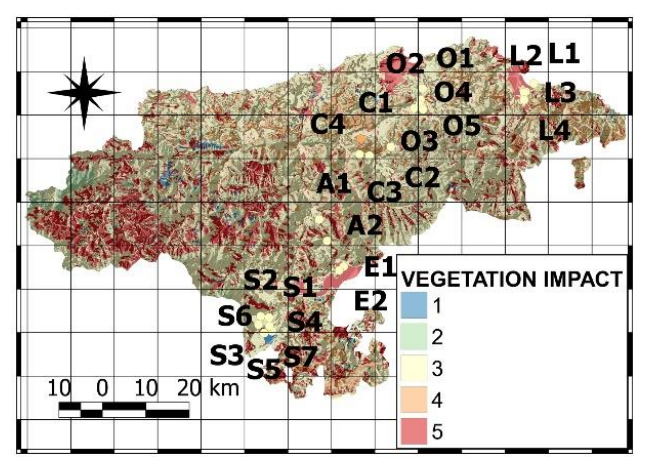

(d)

Figure 2. Maps of impacts according to components: (a) air, (b) ground-soil, (c) water and (d) vegetation.

Table 10. Values of the weighting coefficient and the environmental impact of each component.

\begin{tabular}{|c|c|c|c|c|c|c|c|c|c|c|c|c|}
\hline \multicolumn{13}{|c|}{ Partial Impact Values } \\
\hline Weighting Coefficient & 0.028 & 0.038 & 0.085 & 0.057 & 0.060 & 0.242 & 0.068 & 0.031 & 0.213 & 0.029 & 0.033 & 0.114 \\
\hline Outcrop Component & $\mathrm{A}$ & B & $\mathrm{C}$ & $\mathrm{D}$ & E & $\mathrm{F}$ & G & $\mathrm{H}$ & I & $\mathrm{J}$ & K & $\mathrm{L}$ \\
\hline L1 & 3 & 1 & 1 & 3 & 1 & 5 & 1 & 1 & 5 & 4 & 2 & 5 \\
\hline L2 & 5 & 1 & 1 & 3 & 1 & 5 & 2 & 3 & 5 & 4 & 5 & 3 \\
\hline L3 & 5 & 1 & 1 & 3 & 1 & 3 & 4 & 5 & 5 & 4 & 5 & 3 \\
\hline $\mathrm{L} 4$ & 5 & 1 & 3 & 3 & 1 & 5 & 2 & 3 & 5 & 5 & 5 & 5 \\
\hline $\mathrm{O} 1$ & 4 & 1 & 1 & 3 & 1 & 3 & 2 & 3 & 1 & 3 & 3 & 3 \\
\hline $\mathrm{O} 2$ & 5 & 1 & 1 & 3 & 1 & 3 & 3 & 5 & 5 & 3 & 4 & 5 \\
\hline $\mathrm{O} 3$ & 4 & 2 & 1 & 3 & 1 & 3 & 3 & 3 & 1 & 3 & 4 & 5 \\
\hline O4 & 5 & 2 & 1 & 3 & 1 & 3 & 2 & 3 & 1 & 3 & 3 & 5 \\
\hline O5 & 5 & 2 & 1 & 3 & 1 & 3 & 1 & 3 & 1 & 3 & 3 & 5 \\
\hline $\mathrm{C} 1$ & 4 & 1 & 5 & 4 & 1 & 1 & 1 & 4 & 1 & 3 & 3 & 5 \\
\hline $\mathrm{C} 2$ & 3 & 1 & 3 & 3 & 1 & 1 & 2 & 3 & 5 & 3 & 4 & 5 \\
\hline C3 & 5 & 1 & 1 & 3 & 1 & 1 & 3 & 3 & 5 & 3 & 1 & 5 \\
\hline $\mathrm{C} 4$ & 5 & 1 & 5 & 3 & 1 & 1 & 2 & 3 & 5 & 3 & 4 & 5 \\
\hline A1 & 4 & 1 & 1 & 3 & 1 & 1 & 1 & 1 & 1 & 3 & 1 & 3 \\
\hline A2 & 1 & 1 & 3 & 3 & 1 & 1 & 1 & 4 & 1 & 1 & 1 & 5 \\
\hline E1 & 4 & 1 & 1 & 3 & 1 & 3 & 2 & 3 & 5 & 2 & 3 & 3 \\
\hline E2 & 3 & 1 & 3 & 3 & 1 & 3 & 2 & 3 & 1 & 2 & 4 & 3 \\
\hline S1 & 5 & 1 & 1 & 3 & 5 & 1 & 2 & 1 & 5 & 2 & 3 & 3 \\
\hline S2 & 3 & 1 & 1 & 3 & 5 & 3 & 2 & 3 & 1 & 2 & 1 & 3 \\
\hline S3 & 3 & 1 & 1 & 3 & 5 & 3 & 2 & 3 & 1 & 2 & 5 & 3 \\
\hline S4 & 4 & 1 & 1 & 1 & 5 & 1 & 2 & 3 & 5 & 2 & 5 & 5 \\
\hline S5 & 5 & 1 & 1 & 3 & 5 & 1 & 3 & 3 & 5 & 2 & 1 & 3 \\
\hline S6 & 5 & 1 & 1 & 3 & 5 & 3 & 2 & 5 & 1 & 2 & 4 & 3 \\
\hline S7 & 5 & 1 & 1 & 3 & 5 & 3 & 2 & 3 & 5 & 2 & 4 & 3 \\
\hline
\end{tabular}




\subsubsection{Map of Ground-Soil Impact}

One of the problems that a mining operation causes on the land is the impact that it causes on geomorphological aspects and its active processes in its areas of location and influence. This component is focused on the active geomorphological processes that may exist in the location of the mine, and the consequences on its surroundings. There is an increased risk of rock slides, landslides or subsidence. There is also an increase in the load of sedimentation downstream, produced by the addition of solid material that is derived from the creation of dumps, tracks and infrastructures. There is also an increase in the erosion derived from all the necessary operations required for the exploitation.

The map of ground-soil impact (Figure 2b) uses the existing cartography of these processes. In the case of Cantabria, the database of active processes at scale 1:25,000 is applied. In a general way, it can be stated that this database includes phenomena such as landslide, neotectonic activity, erosion, flooding/sedimentation and subsidence, which are agglutinated into four levels: high, significant, moderate and low. Values of 5, 4, 3 and 2 are assigned, respectively. The results for this component, which are shown in Table 10, are obtained by operating in an analogous way in terms of rasterization and projection of outcrops with respect to the previous one.

\subsubsection{Map of Water Impact}

Mining can cause permanent alteration of surface drainage, due to the creation of dumps and infrastructures, water pollution associated to turbidity from solid particles, the dissolution of toxic elements, and acidification derived from the oxidation and hydration of metallic elements. All of these aspects are due to the creation of the pit, dumps, heavy machinery and transport traffic, the pumping and discharge of effluents, and the implementation of infrastructures.

The map of water impact (Figure 2c) considers the river basins as the main communication routes of the possible affections. Hence, and taking the map of rivers as a basis, three types of impact zones are established: those that are more than $200 \mathrm{~m}$ away from riverbeds, those that are between 100 and $200 \mathrm{~m}$, and those whose distance is less. Values of 1, 3 and 5 are assigned, respectively. This classification is deduced from a work that studies computationally the process of sedimentation of particles from in a 3D longitudinal basin associated to a water treatment plant [41]. Operating in a similar way to that explained for the previous components in terms of rasterization and projection of outcrops, the results are obtained and included in Table 10.

\subsubsection{Map of Vegetation Impact}

Open-pit mining operations produce a permanent impact, with the elimination of existing vegetation and loss of the soil profile in the area where they are located. This implies that there are not catalogued, protected or particularly sensitive plant species in the environmental inventory of the area where they are developed. At the same time, it causes difficulties for its regeneration during the reclamation phase.

For its assessment, a map of predominant plant formations at regional level is made (Figure 2d). A distinction is made between the most predominant formations, and values are assigned to each of them, according to their characteristics and ecological value: urban (5), peatland (5), rock vegetation (2), pre-forest (4), meadow (3), shrubland (3), wetland (5), ferns (1), dump (1), wasteland (1), dunes (5), cultivation (4), heath (3), forest (5) and water (5). Analogous operations as those applied to previous components in terms of rasterization and outcrop projection lead to obtain the results that are also included in Table 10. 


\subsubsection{Map of Fauna Impact}

In open-pit mining, the removal or alteration of fauna habitats cause the displacement or concentration of species or individuals, due to the creation of holes and the construction of tracks. Changes in wildlife behavior are caused by truck and machinery traffic. In addition to this, there is a loss of fertile elements of the soil and its capacity for regeneration.

To determine the map with the impact on fauna (Figure 3a), the regional catalog of endangered species is used. Those that are in danger of extinction are chosen, and among these, those that have cartography associated with their contrasted or probable location are used. The territory is classified according to the probability of existence of these species in three different levels: certain, probable and null. Values of 5, 3 and 1 are assigned, respectively. Hence, the presence of these species in these areas of possible location is assessed. After the application of the aforementioned processes of rasterization and projection of outcrops, the results for this component are obtained and shown in Table 10 .

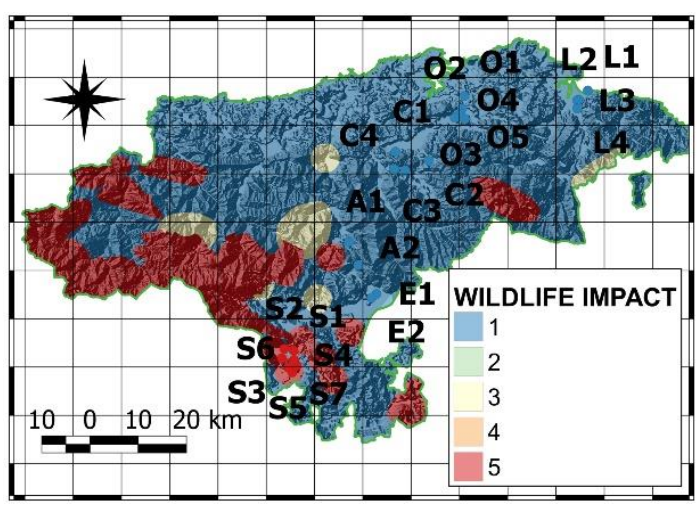

(a)

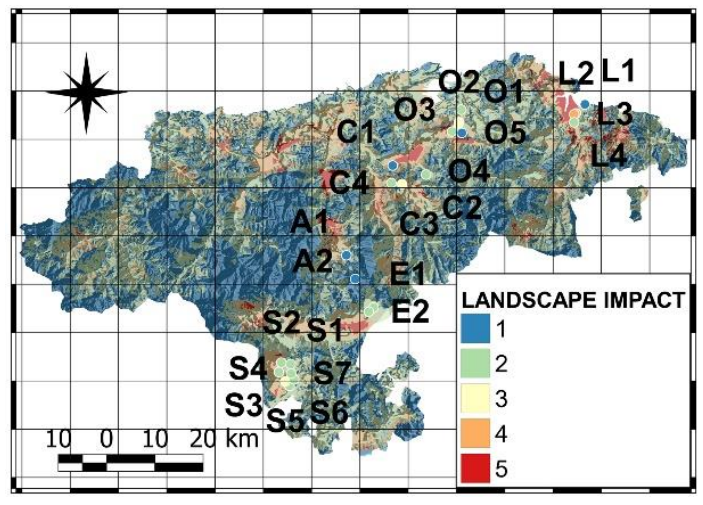

(c)

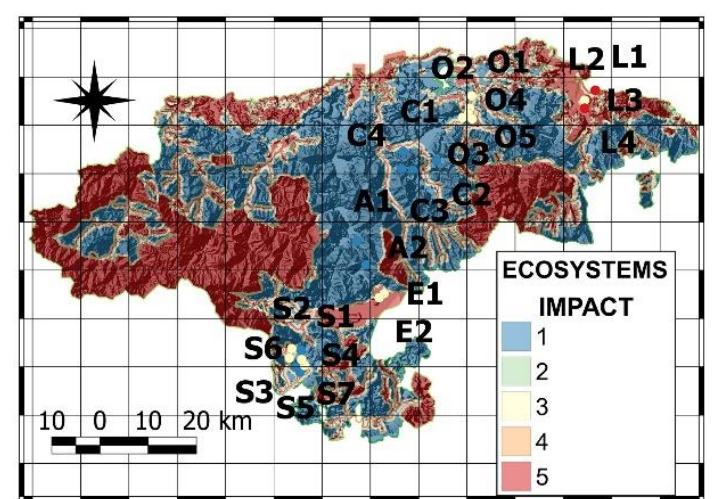

(b)

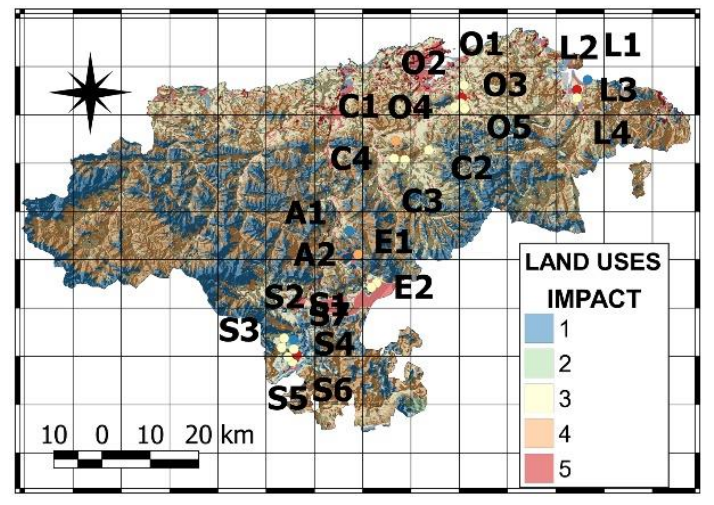

(d)

Figure 3. Maps of impacts according to components: (a) fauna, (b) special ecosystems, (c) landscape and (d) land uses.

\subsubsection{Map of Special Ecosystems Impact}

Protected areas are terrestrial or marine zones that, due to the recognition of their outstanding natural values, are specifically dedicated to nature conservation, and subjected to a special legal regime for their protection. These areas play a decisive role in the conservation of ecosystems, the survival of species, and in the maintenance of ecological processes and the ecosystem assets and services. They are one of the key instruments for the on-site conservation of biodiversity.

Protected natural areas depend, to a large extent, on the sensitivity of national, autonomous and local governments, and can be of very varied typology, such as national parks, natural parks, areas of special interest, special conservation areas, etc. [42]. For the 
determination of the map with the impact of special ecosystems (Figure 3b), a classification of the entire territory into three different groups is proposed: the protection areas themselves, the buffer zone at $500 \mathrm{~m}$ and the rest of the territory. These areas are assigned values of 5, 3 and 1, respectively, to quantify the effect of the component on the environmental impact. This classification is usually set according to the legal constrains that are set by the protective framework of the Ecosystems. In the case of Cantabria, the layer itself includes the different levels of protection. Operating in a similar way that applied to the previous component, the results shown in Table 10 are obtained.

\subsubsection{Map of Landscape Impact}

Mining activities produce a global alteration on the landscape, which is generally serious in the case of the waste dumps, severe when considering the hollows, and of lesser importance in the case of the adjacent infrastructures and buildings. In this case, the analysis is focused on the viewshed areas, as what is not seen can be assimilated to inexistent. For the development of this research, the preliminary nature of the work and the scale that is applied must be considered. The detailed analysis should be developed after selecting the outcrop and defining the mining project, which includes the dimensions and geometry of the exploitation [43]. All the foregoing justifies that the analysis of the viewshed areas has totally different connotations than those normally applied. The most significant conditions can be the location of the observer, which is usually placed in the exploitation. In this case, this is not possible, as its geometry and dimensions are not available. Regarding the distance of observation, it is mainly constrained by the orography of the region where the analysis is developed. In places where it is pronounced, shorter distances are recommended, while longer distances are suitable for flatter regions.

The elaboration of the landscape impact map (Figure 3c) firstly applies the Digital Elevation Model with curves every $25 \mathrm{~m}$, and obtains the viewshed area for a $1.60 \mathrm{~m}$ tall observer located in each of the urban centers of the region (the center of the urban core is considered due to the scale of the work, and its preliminary nature), and an observation radius of $3000 \mathrm{~m}$. This allows us to generate a classified raster that, in the case of Cantabria, provides 17 different classes. That is to say, for level 17, there are 17 towns from which that point of the map is seen with that radius. Then, the reclassification is made according to Table 11, to normalize the results with the rest of the components.

Table 11. Reclassification of the landscape component.

\begin{tabular}{cc}
\hline Viewshed Area & Reclassified Viewshed \\
\hline $0<$ value $\leq 1$ & 1 \\
$1<$ value $\leq 3$ & 2 \\
$3<$ value $\leq 5$ & 3 \\
$5<$ value $\leq 9$ & 4 \\
$9<$ value $\leq 17$ & 5 \\
\hline
\end{tabular}

Analogous operations to those explained for previous components with respect to rasterization and projection provide the results that are included in Table 10.

\subsubsection{Map of Land Uses}

Mining operations have a significant impact on land use, since they produce an irreversible occupation of fertile soil and induce negative edaphic effects in the surroundings of the operation. In this regard, the composition of the map comprises all productive land uses. The impact on them is assessed according to their importance in the productive sector.

The land-use impact map (Figure 3d) comprises the following elements: treeless land, sparsely wooded forest, cultivation, wooded forest and water, which are assigned values of $1,2,3,4$ and 5, respectively. Operating in a similar way to that explained for the previous components in terms of rasterization and outcrop projection, the results are obtained and listed in Table 10. 


\subsubsection{Map of Cultural Heritage Impact}

Within the social and cultural realm, mining activities can have irreversible consequences on cultural, historical, artistic and scientific heritage. For their conservation, it is essential to have an inventory of the region's Assets of Cultural Interest. An Asset of Cultural Interest (ACI) is any property or movable object of artistic, historical, paleontological, archaeological, ethnographic, scientific or technical interest, which has been declared as such by the competent administration. Documentary and bibliographic heritage, archaeological sites and areas, as well as natural sites, gardens and parks of artistic, historical or anthropological value may also be declared as ACIs.

The map of impact on cultural heritage (Figure 4a) classifies the territory according to the normative framework that sets the protective regulations for the ACI. Two different classes are usually considered: the ACIs themselves with a buffer of 200 or $500 \mathrm{~m}$ depending on the type of entity, and the rest of the territory, so that ACIs are given a value of 5 , and the rest of the territory a value of 1 . This approach avoids excluding zones, which can be justified given that in a general study as the one that is proposed in this research, an a priori exclusion of an outcrop is not convenient, as there are changing or flexible regulations that may even be modified over time. Otherwise, a very high value (5) is applied, which practically conditions it in a severe way. The results shown in Table 10 are obtained with the application of a similar treatment to that referred in previous sections.

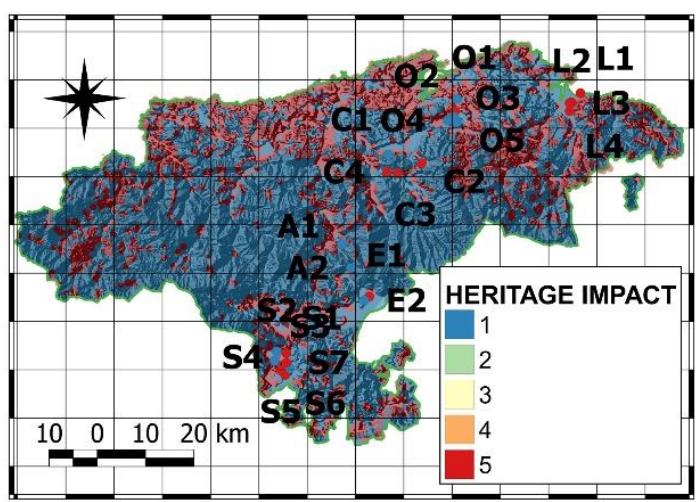

(a)

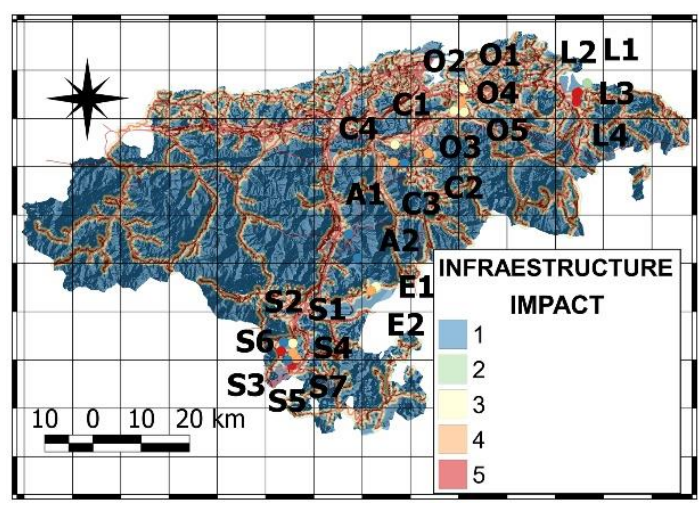

(c)

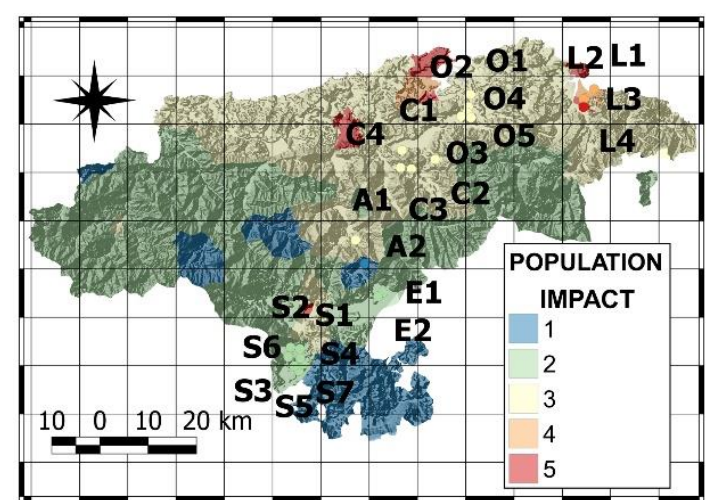

(b)

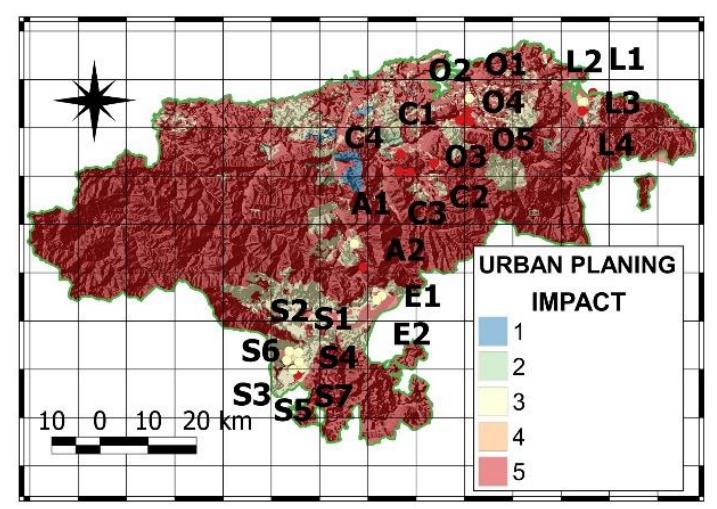

(d)

Figure 4. Maps of impacts according to components: (a) heritage, (b) population, (c) infrastructures and (d) urban planning.

\subsubsection{Map of Population Impact}

All the actions that affect the environment, directly or indirectly, have an impact on people and the population. The assessment is focused on the number of people that is exposed to pollution or a certain environmental risk, given that the larger the population, the greater the risk. Hence, it is proposed to quantify the impact on the basis of the density 
of population of the places where the outcrops are located. Therefore, the municipalities with a higher density of population will have a higher impact value.

The map of the population component (Figure $4 \mathrm{~b}$ ) of the environmental impact classifies each municipality by its population density, and then it rearranges the map into five classes, as shown in Table 12.

Table 12. Reclassification of the population component.

\begin{tabular}{cc}
\hline Population Density & Impact Value \\
\hline $0<$ density $\leq 0.05$ & 1 \\
$0.05<$ density $\leq 0.20$ & 2 \\
$0.20<$ density $\leq 5$ & 3 \\
$5<$ density $\leq 10$ & 4 \\
$10<$ density $\leq 55$ & 5 \\
\hline
\end{tabular}

The results obtained after rasterizing and projecting the outcrops are listed in Table 10.

\subsubsection{Map of Infrastructure Impact}

All infrastructures, whether roads, railways or energy transport, require easement zones and their layout cannot be modified or affected. Under normal conditions, a mining operation cannot be implemented in one of these zones. Any impact on these infrastructures has an economic and social impact at regional and municipal level. The infrastructures to be taken into account are all types of roads, railroad lines, power lines, electrical substations, etc.

The map of infrastructure impact (Figure 4c) is composed of the following elements: buffers for roads of 100, 300, 500 and $700 \mathrm{~m}$, with assigned values of 5, 4, 3 and 2, respectively; buffer at $200 \mathrm{~m}$ from railroads that is provided a value of 5 ; buffer at $100 \mathrm{~m}$ from power lines that is given a value of 5; buffer at $200 \mathrm{~m}$ from electrical substations (with a value of value 5), and the rest of the territory, whose value is 1 . This classification relies in the specific legal framework that recommends distances for the different types of infrastructures. This justifies that it is technically necessary to join the aforementioned maps to generate the total map of infrastructures, in which all the entities are assessed between 1 and 5 . This total map of infrastructures is converted to raster format. Operating in a similar way to the previous components provides the results that are included in Table 10.

\subsubsection{Map of Urban Planning Impact}

One of the priority aspects before starting any mining activity is to take into account the management of each territory. In this sense, the diversity of legislation depends to a large extent on the country, region or municipality in which this methodological proposal is intended to be applied, and on the sensitivity of these government with mining. It is also worth remembering that the purpose of this research is not to look for exclusion zones, as the tool that allows us to search for these exclusion zones is the EI. This research looks for the planning component of the environmental impact in a quantitative way.

The map of urban planning impact (Figure 4d) comprises the elements that are shown in Table 13, which are defined within the current legislation on land use planning in Cantabria. 
Table 13. Classification of the urban planning component.

\begin{tabular}{cc}
\hline Land Classification & Impact Value \\
\hline - Specially protected rustic land. & \\
- Consolidated urban land. & 5 \\
- Limited land for development. & \\
- Unconsolidated urban land. & 3 \\
\hline - Rustic land of ordinary protection. & 2 \\
- Non-urbanizable land 3 forest interest. & \\
- Undeveloped agricultural land. & \\
\hline - Undeveloped non-urbanizable land of normal regime. \\
- Forest and livestock land (far from the nucleus). \\
- Non-urbanizable land with mining protection. \\
- Non-urbanizable land with special mining-farming protection 2. \\
- Undeveloped land with the protection for extractive activities. \\
- Undeveloped land 2 of forestry interest and mining extraction. \\
- Undeveloped land class IV. Open-pit quarries.
\end{tabular}

Analogous processing, in terms of rasterization and projection of outcrops, provides the results that are shown in Table 10.

\subsection{Results of the Environmental Impact Index}

The GIS tool shows its potential in the preparation of the map of total environmental impact index, especially in the map algebra. It allows for the superimposing of all the impact maps created in the previous section, and making the weighted sum of them with their weighting coefficients, which were established in the pairwise comparison matrix, and whose consistency was duly justified. The values of impact for each component are shown in Table 10. All the foregoing leads to the generation of an impact map with all the components properly weighted.

Once again, the map with the outcrop points can be projected on the raster map of reclassified environmental impact (Figure 5), obtaining the total impact value for each outcrop.

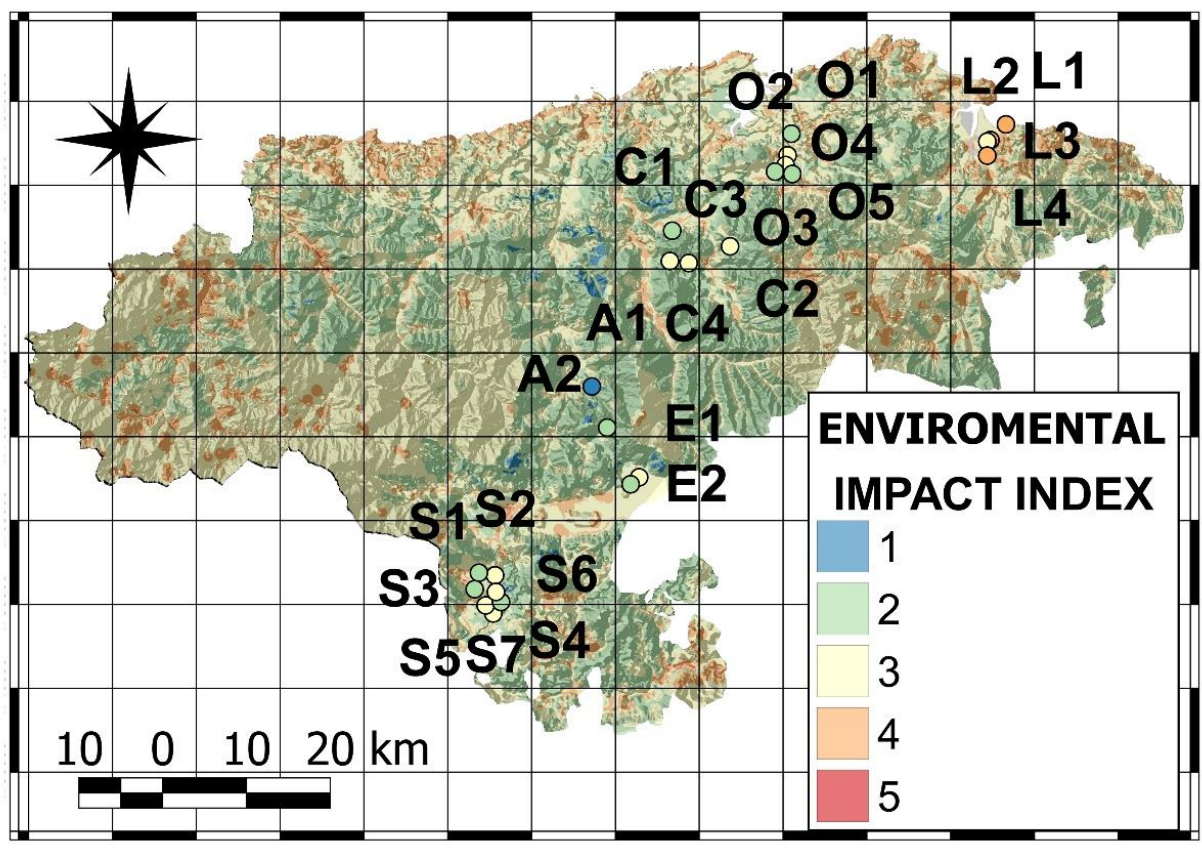

Figure 5. Map of reclassified environmental impact. 
After establishing all the components of the environmental impact in each map, the weightings are applied with the weights obtained from the analysis with the AHP multicriteria method (Table 10). The final impact value (Table 14, second column) is obtained by adding up the values of all the components. Since the impact values range from 1.483 to 4.055 , they are grouped into the five classes, according to the criteria set (Table 15).

Table 14. Results of the environmental impact for each outcrop.

\begin{tabular}{|c|c|c|c|}
\hline Outcrop & Total Impact & Reclassified Total Impact & Traditional Impact \\
\hline L1 & 3.568 & 4 & 4 \\
\hline L2 & 3.627 & 4 & 4 \\
\hline L3 & 3.342 & 3 & 4 \\
\hline L4 & 4.055 & 4 & 4 \\
\hline O1 & 2.166 & 2 & 4 \\
\hline $\mathrm{O} 2$ & 3.439 & 3 & 4 \\
\hline $\mathrm{O} 3$ & 2.534 & 3 & 2 \\
\hline $\mathrm{O} 4$ & 2.460 & 2 & 2 \\
\hline O5 & 2.392 & 2 & 2 \\
\hline C1 & 2.271 & 2 & 2 \\
\hline C2 & 2.938 & 3 & 0 \\
\hline C3 & 2.791 & 3 & 2 \\
\hline C4 & 3.165 & 3 & 2 \\
\hline A1 & 1.483 & 1 & 0 \\
\hline A2 & 1.836 & 2 & 1 \\
\hline E1 & 2.990 & 3 & 4 \\
\hline E2 & 2.314 & 2 & 4 \\
\hline S1 & 2.710 & 3 & 0 \\
\hline S2 & 2.283 & 2 & 1 \\
\hline S3 & 2.417 & 2 & 0 \\
\hline S4 & 2.926 & 3 & 1 \\
\hline S5 & 2.774 & 3 & 1 \\
\hline S6 & 2.502 & 3 & 0 \\
\hline S7 & 3.291 & 3 & 4 \\
\hline
\end{tabular}

Table 15. Criteria applied to group the values of environmental impact by classes.

\begin{tabular}{cc}
\hline Calculated Impact Value & Reclassified Impact Value \\
\hline $0<$ value $\leq 1.50$ & 1 \\
$1.50<$ value $\leq 2.50$ & 2 \\
$2.50<$ value $\leq 3.50$ & 3 \\
$3.5<$ value $\leq 4.50$ & 4 \\
$4.50<$ value $\leq 5$ & 5 \\
\hline
\end{tabular}

As a result of this reclassification, the final value of the environmental impact for each outcrop is obtained (Table 14, third column), which allows us to generate the map of reclassified environmental impact (Figure 5).

The final value of the environmental impact of each outcrop can be compared with the one that would have been used traditionally (Table 14, fourth column). It should be noted that the comparison between the impact obtained with the proposed methodology (final reclassified impact, Table 14, third column) and the traditional impact obtained for the same outcrops in previous works of research (Table 14, fourth column) shows significant differences between the resulting values for the environmental factor. As this is semiobjective comparison, in order to apply the results it must be taken into account that the variations in the environmental factor produce differences in the EI. Depending on the methodology that is used to determine the EI, the environmental impact implies the 30\% of the weighting of other factors. Hence, it can be assured that the absolute variation of the EI can be of about $30 \%$ of the variations of the environmental factor. In the light of results, 
this can be considered as very significant. This reflects the strengths of the process that was established to determine the environmental factor within the EI.

\section{Discussion}

Several interpretations can be presented for the results that were obtained from the development of this research, which is focused on a new methodological proposal that allows for the search for tools to improve the determination of the environmental impact as a factor within the EI, and its application to the current case of the ophites in Cantabria.

- The framework that comprises this research is focused on a preliminary analysis of the environmental factor, which allows us to calculate the EI at an early stage of the mining exploration. During this phase, the analysis is made on a general basis, as most of the prospecting techniques have not been applied yet, and the mining project itself has not been developed. This makes it necessary to apply data which are characterized by a pronounced general nature. Another relevant issue is the geographic scope of the research, which is focused on a specific Spanish administrative region, Cantabria. This allows for the application of a single regulatory framework, the same cartographic base, etc. If several administrative regions were involved, this could vary and should be considered.

- Once the components that most affect the environment in the area of extractive activities of ophitic materials were chosen, the multi-criteria method (i.e., AHP) was applied to determine the weighting to be used through an analytical process with objective criteria. The proposal of the matrix of components, as well as its pairwise comparison and the weighting itself were validated through the analysis of the consistency ratio of the matrix itself, as proposed in the methodology.

- After establishing the components and their respective weighting coefficients, the main criteria for the definition of each component were set. A detailed analysis of each criterion involved is required. In this regard, it should be taken into account that the more components there are, the better the environmental coefficient will represent the reality of the impact. At a second level, the more criteria used in the definition of the component, the better the component will be represented, and the more representative the environmental coefficient will be.

- Since all the processing is done with GIS tools, the elaboration of all the maps, which involves a great workload, is done in a quasi-automatic form. However, the thematic data and a proper normalization of the results are required to be able to apply the map algebra, as proposed by the methodology. The whole procedure was applied according to it and carried out successfully, obtaining the value of each component of the environment for every outcrop analyzed.

- Once the value and weighting of every component is obtained, the final value of the environmental coefficient for each outcrop is determined. Significant differences in the results are detected when compared with the environmental coefficients traditionally used. These significant differences are inevitably transferred to the EI of the outcrops, since the environmental coefficient can represent up to $30 \%$ of the weight in its calculation. All of this was taken into account in the pairwise comparison and the application of Saaty scale, and a conservative model was chosen. The adoption of a riskier alternative could possibly have resulted in even more significant differences.

- The methodology has a strong dependence on the components and the criteria of the components themselves chosen for each factor, since variations in any of these components cause the result to vary. Both the factors and the components are at the discretion of the developers, as they must be set according to their experience and the regional setting in which the outcrops are located. Nevertheless, by applying the methodology proposed in this research, variations are reduced to a minimum, especially with the final standardization. 


\section{Conclusions}

Nowadays, the decision to start up an extractive activity is made on the basis of an index called exploitability, which helps in making this decision and takes into account a series of factors such as reserves, accessibility, environment, etc. Traditionally, the environmental factor has a weight that, depending on the authors, can reach $30 \%$. This reflects the importance of environmental sustainability in making this type of decision. The different authors who deal with these issues analyze the environment in a simple way, relying mainly on the premature state in which the project is in, but as demonstrated in this research, the analysis of the environmental factor can be significantly improved in a relatively simple and economical way by using the powerful multi-criteria analysis and GIS tools that are now available to any user with an appropriate methodology.

The methodological proposal resulting from this research fills a gap that currently exists in the evaluation of the environmental factor for the determination of the EI. It proposes the use of all the environmental components that can be considered, depending on the type of mining and environment where the outcrops are located. This proposal assumes that, in certain cases, a number of components can be taken into account. Given the difficulty of weighting them, a method (i.e., AHP) is proposed to objectively achieve it and also to check if this weighting is consistent or not. In addition to the foregoing, a methodology was implemented, to select the most relevant criteria to be considered for each component of the environmental factor, along with the procedure to develop its normalization, and the subsequent application of the map algebra to obtain a final map with the assessment of the environmental factor, from which the values of all the outcrops to be analyzed can be obtained.

The differences resulting from the use of traditional methodologies and the proposal that is derived from this research for the determination of the environmental factor and the EI support multi-criteria analysis as a fundamental tool for decision making. Both the environmental factor and the EI that are calculated by applying the methodological proposal of this research are much more representative than those obtained with traditional methods. In addition, it can be considered as a working methodology for the management of mining areas, and it is also applicable in other contexts.

It should be noted that this methodological proposal is also innovative, because it proposes to carry out the environmental analysis, not after the decision on the site has been made, but before deciding on the outcrop to be mined. This implies including the environmental analysis from the initial moment when the decision to start the mining operation is made, thus helping to ensure that it is present from the beginning. In addition to the foregoing, the different environmental cartographic bases that have been developed for the development of the multi-criteria analysis of the several components that have been considered, and specially the map of the environment factor with all its components, can be a very relevant set of thematic mapping for the location of suitable areas for mining.

Author Contributions: Conceptualization, Gema Fernández-Maroto and Julio Manuel de Luis-Ruiz; methodology, Gema Fernández-Maroto and Julio Manuel de Luis-Ruiz; software, Benito Ramiro SalasMenocal and Raúl Pereda-García; validation, Julio Manuel de Luis-Ruiz and Rubén Pérez-Álvarez; formal analysis, Julio Manuel de Luis-Ruiz and Gema Fernández-Maroto; investigation, Julio Manuel de Luis-Ruiz, Benito Ramiro Salas-Menocal and Gema Fernández-Maroto; resources, Julio Manuel de Luis-Ruiz; data curation, Benito Ramiro Salas-Menocal and Julio Manuel de Luis-Ruiz; writingoriginal draft preparation, Julio Manuel de Luis-Ruiz; writing—review and editing, Julio Manuel de Luis-Ruiz, Gema Fernández-Maroto, Rubén Pérez-Álvarez and Raúl Pereda-García; visualization, Benito Ramiro Salas-Menocal, Raúl Pereda-García and Rubén Pérez-Álvarez; supervision, Julio Manuel de Luis-Ruiz and Gema Fernández-Maroto. All authors have read and agreed to the published version of the manuscript.

Funding: This research received no external funding.

Institutional Review Board Statement: Not applicable.

Informed Consent Statement: Not applicable. 
Data Availability Statement: The data presented in this study are openly available in the repository of the University of Cantabria, at: https: / / disco.unican.es/public/?folder=15033ce7 accessed on 20 March 2021. The following password is required: ISPRS Int. J. Geo-Inf.

Conflicts of Interest: The authors declare no conflict of interest.

\section{References}

1. Suh, J.; Kim, S.-M.; Yi, H.; Choi, Y. An overview of GIS-based modeling and assessment of mining-induced hazards: Soil, water, and forest. Int. J. Environ. Res. Public Health 2017, 14, 1463. [CrossRef]

2. Risk, C.; Zamaria, S.A.; Chen, J.; Ke, J.J.; Morgan, G.; Taylor, J.; Larsen, K.; Cowling, S.A. Using geographic information systems to make transparent and weighted decisions on pit development: Incorporation of interactive economic, environmental, and social factors. Can. J. Earth Sci. 2020, 57, 1103-1126. [CrossRef]

3. Kim, S.M.; Choi, Y.; Suh, J.; Oh, S.; Park, H.D.; Yoon, S.H.; Go, W.R. ArcMine: A GIS extension to support mine reclamation planning. Comput. Geosci. 2012, 46, 84-95. [CrossRef]

4. Nowak, M.M.; Dziób, K.; Ludwisiak, L.; Chmiel, J. Mobile GIS applications for environmental field surveys: A state of the art. Glob. Ecol. Conserv. 2020, 23, e01089. [CrossRef]

5. Paraskevis, N.; Roumpos, C.; Stathopoulos, N.; Adam, A. Spatial analysis and evaluation of a coal deposit by coupling AHP \& GIS techniques. Int. J. Min. Sci. Technol. 2019, 29, 943-953. [CrossRef]

6. Haslam, P.A. Bigger data and quantitative methods in the study of socio-environmental conflicts. Sustainability 2020, $12,7673$. [CrossRef]

7. Ranjith Premasiri, H.M.; Dahanayake, T. Development of GIS based model for locating sustainable construction aggregate mining sites: Case study from Sri Lanka. In Remote Sensing Enabling Prosperity, Proceedings of the 39th Asian Conference on Remote Sensing (ACRS 2018), Kuala Lumpur, Malaysia, 15-19 October 2018; Asian Association on Remote Sensing: Klong Luang, Thailand, 2019.

8. Yuan, H.; Nturambirwe, J.F.I. Research and application of geographical information system and data mining technology in monitoring and evaluation of natural geographical environment. J. Mine Vent. Soc. S. Afr. 2020, 73, 135-139.

9. Fernández-Maroto, G.; De Luis-Ruiz, J.M.; Pereda-García, R.; Malagón Picón, B.; Pérez-Álvarez, R. Multicriteria analysis for the determination of the exploitability index of industrial aggregate outcrops. Arch. Min. Sci. 2020, 65, 103-115. [CrossRef]

10. Murdzek, R.; Malik, H.; Leśniak, A. Ground Subsidence Information as a Valuable Layer in GIS Analysis. E3S Web Conf. 2018, 36, 02006. [CrossRef]

11. Barettino, D. Ordenación Minero-Ambiental de Recursos de Rocas Industriales. Aplicación a la Reserva Estatal de Pizarras de La Cabrera (León). Ph.D. Thesis, Polytechnic University of Madrid, Madrid, Spain, 2002.

12. Díaz de Terán, J.R.; González Lastra, J.R. Un método de Evaluación y de Jerarquización de los Afloramientos de Rocas Industriales. In Proceedings of the I Reunión Nacional de Geología Ambiental y Ordenación del Territorio, vol. Comunicaciones, Santander, Spain, 19-23 May 1980; Sociedad Española de Geología y Ordenación del Territorio: Santander, Spain, 1980.

13. Gómez Orea, D. Evaluación de Impacto Ambiental; Agrícola Española: Madrid, Spain, 1998.

14. Oliveira Sousa, L.M. Estudo da Fracturaçao e das Características Físico-Mecânicas de Granitos da Regiao de Trás-os-Montes com Vista à sua Utilizaçao como Rocha Ornamental. Ph.D. Thesis, Universidade de Trás-Os-Montes e Alto Douro, Vila Real, Portugal, 2000.

15. Muñoz de la Nava, P.M.; Escudero, J.A.R.; Suárez, I.R.; Romero, E.G.; Rosa, A.C.; Moles, F.C.; Martínez, M.P.G. Metodología de investigación de rocas ornamentales: Granitos. Bol. Geol. Min. 1989, 100, 129-149.

16. Berry, P.; Pistocchi, A. A Multicriterial Geographical Approach for the Environmental Impact Assessment of Open-Pit Quarries. In Proceedings of the 6th International Conference of Enviromental Issues and Mangement of Waste in Energy and Mineral Production (SWEMP 2000), Calgary, AB, Canada, 30 May-2 June 2000; A.A: Balkema Publisher: Rotterdam, The Netherlands, 2000.

17. Bandini, A.; Berry, P.; Dacquino, C. Implementation of a Database of Risk Assesment of Abandoned Italian Mining Sites. In Proceedings of the 11th International Symposyum on Environmetal Issues and Waste Management in Energy and Mineral Production (SWEMP 2000), Banff, AB, Canada, 16-19 September 2009; The Reading Matrix, Inc.: Irvine, CA, USA, 2009.

18. Rudke, A.P.; Sikora de Souza, V.A.; Santos, A.M.D.; Freitas Xavier, A.C.; Rotunno Filho, O.C.; Martins, J.A. Impact of mining activities or areas of environmental protection in the southwest of the Amazon: A GIS- and remote sensing-based assessment. J. Environ. Manag. 2020, 263, 110392. [CrossRef] [PubMed]

19. Fernández Maroto, G. Comportamiento como Árido para Pavimento de Ofitas de Cantabria. Ph.D. Thesis, University of Oviedo, Oviedo, Spain, 2002.

20. Hernández-Durán, G.; Arranz-González, J.C.; Vega-Panizo, R.D.L. El análisis del potencial geológico de rocas industriales en proyectos de planificación territorial: Una revisión. Bol. Geol. Min. 2014, 125, 475-492.

21. Kwinta, A.; Gradka, R. Mining exploitation influence range. Nat. Hazards 2018, 94, 979-997. [CrossRef]

22. Lin, Y.; Hoover, J.; Beene, D.; Erdei, E.; Liu, Z. Environmental risk mapping of potential abandoned uranium mine contamination on the Navajo Nation, USA, using a GIS-based multi-criteria decision analysis approach. Environ. Sci. Pollut. Res. 2020, 27, 30542-30557. [CrossRef]

23. Wnorowski, A.; Aklilu, Y.; Harner, T.; Schuster, J.; Charland, J. Polycyclic aromatic compounds in ambient air in the surface minable area of Athabasca oil sands in Alberta (Canada). Atmos. Environ. 2021, 244, 117897. [CrossRef] 
24. Martínez-Toledo, A.; González-Mille, D.; García-Arreola, M.; Cruz-Santiago, O.; Trejo-Acevedo, A.; Ilizaliturri-Hernández, C. Patterns in utilization of carbon sources in soil microbial communities contaminated with mine solid wastes from San Luis Potosi, Mexico. Ecotoxicol. Environ. Saf. 2021, 208, 111493. [CrossRef]

25. Tomiyama, S.; Igarashi, T.; Tabelin, C.; Tangviroon, P.; Li, H. Modeling of the groundwater flow system in excavated areas of an abandoned mine. J. Contam. Hydrol. 2020, 230, 103617. [CrossRef]

26. Zhixin, S.; Gangfu, S.; Wenzhong, T.; Dandan, Y.; Yu, Z.; Yaoyao, Z.; Jinghao, W.; Yulu, M. Molybdenum contamination dispersion from mining site to a reservoir. Ecotoxicol. Environ. Saf. 2021, 208. [CrossRef]

27. Xinguang, Y.; Xilai, L.; Mingming, S.; Liqun, J.; Huafang, S. The effects of replaced topsoil of different depths on the vegetation and soil properties of reclaimed coal mine spoils in an alpine mining area. Isr. J. Ecol. Evol. 2019, 65, 1-14. [CrossRef]

28. Jorba, M.; Ninot Sugrañes, J.; Bracho, C. Interacciones en espacios mineros restaurados: Vegetación y avifauna. Ecosistemas 2019, 28, 78-81. [CrossRef]

29. Hernandez-Santin, L.; Rudge, M.; Bartolo, R.; Whiteside, T.; Erskine, P. Reference site selection protocols for mine site ecosystem restoration. Restor. Ecol. 2020, 29, e13278. [CrossRef]

30. Chen, W.; Li, X.; He, H.; Wang, L. Assessing Different Feature Sets' Effects on Land Cover Classification in Complex Surface-Mined Landscapes by ZiYuan-3 Satellite Imagery. Remote Sens. 2018, 10, 23. [CrossRef]

31. Brandi, I.; Barbosa, M.; Guimarães de Paula, R.; Araújo, R.; Vieira de Moura, R.; Mota de Lima, H. Instrumented geotechnical monitoring of a natural cave in a near mine operation-Towards a sustainable approach to mining and preservation of speleological heritage. J. Clean. Prod. 2019, 239, 118040. [CrossRef]

32. Doya, R.; Nakayama, S.S.M.M.; Hokuto, N.; Haruya, T.; Yabe, J.; Muzandu, K.; Yohannes, Y.B.; Kataba, A.; Zyambo, G.; Ogawa, T.; et al. Land Use in Habitats Affects Metal Concentrations in Wild Lizards Around a Former Lead Mining Site. Environ. Sci. Technol. 2020, 54, 14474-14481. [CrossRef] [PubMed]

33. Martins, N.; Bollinger, C.; Harper, R.; Ribeiro, R. Effects of acid mine drainage on the genetic diversity and structure of a natural population of Daphnia longispina. Aquat. Toxicol. 2009, 92, 104-112. [CrossRef]

34. Moridi, M.A.; Kawamura, Y.; Sharifzadeh, M.; Chanda, E.K.; Wagner, M.; Jang, H.; Okawa, H. Development of underground mine monitoring and communication system integrated ZigBee and GIS. Int. J. Min. Sci. Technol. 2015, 25, 811-818. [CrossRef]

35. Gałaś, A.; Tyszer, M.; Gałaś, S. Using GIS to Predict Potential Environmental Conflicts in the Colca and Andagua Volcanoes Geopark (Peru). In Public Recreation and Landscape Protection-With Nature Hand in Hand Conference Proceeding, Krtiny, Czech Republic, 2-4 May 2018; Fialová, J., Ed.; Mendel University in Brno-Czech Society of Landscape Engineers: Brno, Czech Republic, 2018.

36. Saedpanah, S.; Amanollahi, J. Environmental pollution and geo-ecological risk assessment of the Qhorveh mining area in western Iran. Environ. Pollut. 2019, 253, 811-820. [CrossRef] [PubMed]

37. Saaty, T.L. How to make a decision: The analytic hierarchy process. Eur. J. Oper. Res. 1990, 48, 9-26. [CrossRef]

38. Aguarón, J.; Escobar, M.T.; Moreno-Jiménez, J.M. Consistency Stability Intervals for a judgement in AHP Decision Support Systems. Eur. J. Oper. Res. 2001, 45, 382-393. [CrossRef]

39. Aznar Bellver, J.; Guijarro Martínez, F. Nuevos Métodos de Valoración. Modelos Multicriterio; Editorial Universitat Politècnica de València: Valencia, Spain, 2005.

40. Kellogg, C.A.; Griffin, D.W. Aeorobiology and the Global Transport of Desert Dust. Trends Ecol. Evol. 2006, 21, 638-644. [CrossRef] [PubMed]

41. Al-Sammarraee, M.; Chan, A.; Salim, S.M.; Mahabaleswar, U.S. Large-eddy Simulations of Particle Sedimentation in a Longitudinal Sedimentation Basin of a Water Treatment Plant. Part I: Particle settling performance. Chem. Eng. J. 2009, 152, 307-314. [CrossRef]

42. Knopff, K.; Bede, L.C.; Arruda, L.; Alves, T.; Simons, B. Methods for Postdisaster Impact Assessment: A Case Study of the Impacts at the Fundão Dam Failure on Terrestrial Species Threatened with Extinction. Integr. Environ. Assess. Manag. 2020, 16, $1551-3777$. [CrossRef] [PubMed]

43. Dentoni, V.; Massacci, G. Assessment of Visual Impact Induced by Surface Mining with Reference to a Case Study Located in Sardinia, Italy. Environ. Earth Sci. 2013, 68, 1485-1493. [CrossRef] 